\title{
Un análisis fenomenológico-levinasiano de la cuestión del tiempo en Nadie nada nunca de J. J. Saer.
}

\author{
A phenomenological-Levinasian analysis of the question of time in \\ Nadie nada nunca by J. J. Saer.
}

Gisela Suaro*

\begin{abstract}
Resumen: Este artículo explora las diferentes significaciones del tiempo en la obra Nadie nada nunca de Juan José Saer y la singularidad de su escritura. Propone una aproximación interdisciplinar que articula elementos de crítica literaria y conceptos de la filosofía de Emmanuel Levinas a fin de elucidar los potenciales sentidos ontológico, estético y político del fenómeno temporal en la novela estudiada. El concepto levinasiano de diacronía es utilizado como figura hermenéutica esencial para comprender y caracterizar el estilo de escritura saeriana, que da cuenta de la experiencia del presente que afecta a los personajes, y de la imagen del tiempo discontinuo implícita en la obra. Se retoma, entonces, desde una perspectiva fenomenológica, los conceptos de presente, instante, memoria y conciencia trabajados en los estudios literarios sobre la obra de Saer, para encontrar, más allá de una concepción ontológica de la materialidad del tiempo, un recurso estético que permite pensar la constitución del tiempo y de la subjetividad en el contexto de la dictadura militar en Argentina.
\end{abstract}

Palabras clave: Fenomenología, Literatura, Tiempo, Dictadura

Abstract: This paper explores the different meanings of time in the work Nadie nada nunca by Juan José Saer and the uniqueness of his writing. It proposes an interdisciplinary approach that articulates elements of literary criticism and concepts of the philosophy of Emmanuel Levinas in order to elucidate the potential ontological, aesthetic and political senses of the temporal phenomenon in the novel studied. The Levinasian concept of diachrony is used as an essential hermeneutical figure, to

\footnotetext{
* Doctora en Filosofía por la Universidad Nacional de Córdoba. Docente adjunta de Antropología Filosófica en la carrera del Profesorado Universitario de Educación Superior en Filosofía de la Universidad Nacional de General Sarmiento (UNGS). Ha publicado artículos de revistas, capítulos de libros y compilaciones sobre el problema del tiempo y del cuerpo en la fenomenología francesa, más específicamente, en diálogo con el pensamiento levinasiano. Dirección electrónica: gsuazo@campus.ungs.edu.ar
} 
understand and characterize the Saerian writing style that accounts for the experience of the present that affects the characters, and the image of the discontinuous time implicit in the work. The concepts of present, instant, memory and consciousness researched in literary studies on the work of Saer, are selected in order to find, beyond ontological conception of the materiality of time, an aesthetic resource that allows us to think about the constitution of time and subjectivity in the context of the military dictatorship in Argentina.

Keywords: Phenomenology, Literature, Time, Dictatorship

\section{Introducción}

Nadie nada nunca, de Juan José Saer, explora tal vez diferentes sentidos del tiempo y, especialmente, de la dimensión del presente a través de un archipormenorizado abordaje de las vivencias que los personajes tienen de cada "aquí y ahora". Aplicando un enfoque interdisciplinar que pone en relación la prosa de esta novela con el pensamiento de Emmanuel Levinas, buscamos interpretar filosóficamente las ideas del tiempo plasmadas en el relato y los rasgos de la escritura adoptada para referirse a ellos. Recuperando terminología de la fenomenología levinasiana, denominamos diacrónicos a dicho registro de escritura y al modo de transcurrir de los acontecimientos sobre los que discurre. Desde esta perspectiva filosófica, la diacronía indica el modo de efectuarse de ciertos fenómenos sensibles que introducen un corte y detenimiento de la eficacia del tiempo de la representación anunciando, además, una dimensión de vivencias refractarias a la conciencia capaces de contradecir su hegemonía y, con ello, la noción de sujeto fundamento y auto-fundante de la Modernidad.

Este concepto de diacronía encuentra una explicitación en Saer, en su forma de referir a la dimensión material de la existencia y en cómo ella afecta a los personajes. Se trata, entonces, de redescubrir, más allá de su estricta significación estética, posibles sentidos de la escritura saeriana a partir de un análisis en clave levinasiana de la visión del tiempo plasmada en la obra. Ciertamente, en ella, el pasarse diacrónico se verifica en las descripciones del instante, en el que la sensibilidad es afectada, por un lado, por la dimensión material de la existencia como un continum cósmico ciego, inescrutable e impersonal, que concierne concretamente a los personajes de la historia como una amenaza de despersonalización y como una faena ineluctable; por otro 
lado, el instante marca el acontecimiento de vinculación con la alteridad a partir de la cual recobra sentido el tiempo del relato. El trabajo procura indagar también acerca del potencial sentido político de estas visiones de lo temporal y del fenómeno de la despersonalización visualizados en la novela, teniendo en cuenta, especialmente, que el contexto en el que se desarrolla la trama (y su escritura) es el de la última dictadura cívico-militar argentina.

\section{Pensamiento y escritura diacrónicos en Levinas y Saer}

En la obra filosófica levinasiana, la reflexión sobre los sentidos del tiempo es recurrente y estructural. Este autor distingue dos sentidos del tiempo inconmensurables entre sí; a saber, por un lado, el tiempo interno (trascendental) de la conciencia en el que y por el que se organizan las vivencias del sujeto y se realiza la síntesis de la unidad del objeto, al que le denomina tiempo sincrónico (syn-krónos). Y, por otro lado, un tiempo caracterizado como el acaecer propio de acontecimientos emancipados de las reglas del tiempo interno y, por ende, refractario al orden de la representación en sus diferentes niveles (percepción, aprehensión, conceptualización, etc.). Esta segunda forma del tiempo lleva el nombre de tiempo diacrónico (dia-krónos), porque atraviesa, corta e interrumpe la eficacia del tiempo entendido como cronología que permite la objetivación y la organización del relato transparente a la razón.

Lo diacrónico, cabe subrayar, se vincula a este efectuarse que no se reduce al pensamiento, se resiste a él, pero le concierne. Podemos decir, entonces, que a la anarquía respecto de la razón que cualifica al lapso diacrónico, se le agrega, también el ingrediente de la conminación que ejerce sobre el dominio del pensamiento. Para Levinas, si bien toda sensación es anárquica, ella es diacrónica en la medida en que conmueve el plano lógico y esta conminación tendrá en el autor la forma de la trascendencia comportada por el otro hombre.

Por efectuarse en un plano ajeno e indiferente al de la capacidad de representación de la conciencia, los eventos diacrónicos se presentan inadecuados a la percepción y al entendimiento. En consecuencia, reflexionar sobre lo diacrónico implica una atención del pensamiento sobre aquello que, por principio, le es esquivo y demanda una reducción de sus análisis al universo 
de vivencias sensibles que en fenomenología se denominan no-intencionales. ${ }^{1}$ Este tipo de vivencias se identifican con las impresiones en su pura inmediatez, desprovistas de sentidos o significaciones emanadas de la conciencia. Escribir sobre lo diacrónico es decir lo indecible y, entonces, en cierta forma, es traicionarlo en alguna simplificación. No obstante, la única manera de referirse a lo diacrónico es abordarlo desde el lenguaje simbólico, es decir someterlo a "la indiscreción sierva del lenguaje abusivo que divulga o profana lo indecible". ${ }^{2}$ Por ende, se trata de una escritura que se mantiene en la "situación extrema del pensamiento diacrónico"3, abocada a la difícil tarea de describir la vida sensible previa a toda articulación cognitiva.

La escritura de Saer en Nadie nada nunca enfrenta este desafío a través de lo que denominamos una propuesta de escritura diacrónica. Ella se visualiza, concretamente, en los recurrentes pasajes donde la trama se detiene en una descripción apoteótica del detalle de momentos en los que la capacidad de la conciencia de aprehender y dar cuenta de la situación vivida se disipa hasta presentarse como la experiencia de una opacidad insuperable e innombrable.

\footnotetext{
${ }^{1}$ Vale destacar que para la corriente fenomenológica el concepto de vivencia (Erlebnis) es cardinal, puesto que señala el campo de exploración al que se aplica la reflexión filosófica. La conciencia toda es comprendida como una corriente de vivencias, y las vivencias, a su vez, se caracterizan por ser trascendentales y no psicológicas, puras y no empíricas. Es decir, las vivencias, en cuanto datos puros a los que se vuelve la indagación fenomenológica, no son realidades psíquicas que forman parte del mundo trascendente, natural y objetivo que investiga la psicología empírica, sino los actos dadores de sentido a partir de los cuales el propio mundo y todos los objetos del mundo son significados como tales. Según Edmund Husserl, autor original del programa fenomenológico, las vivencias puras concretas poseen una dualidad: una forma intencional y una materia sensible. La forma intencional es el acto dador de sentido que anima la materia sensible (la sensación) transformándola de mera impresión primaria desprovista de formas en el aparecer de algo, de un objeto para la conciencia (ver Husserl, Ideas relativas a una fenomenología pura y una filosofía fenomenológica, México, Fondo de Cultura Económica, 1992, p. 205). Las vivencias intencionales son los actos de conciencia que revisten de sentido a las sensaciones (contenidos primarios) que por sí sola constituyen "materias sin forma" (Ibid., p. 204). Las vivencias no intencionales son, por ende, los datos sensibles.

2 Levinas, Emmanuel, De otro modo que ser o más allá de la esencia, Salamanca, Editorial Sígueme, 2003, p. 96.

3 Ibid., p. 50.
} 
Escenario repetido a lo largo del texto y que se advierte claramente, por ejemplo, cuando el narrador describe la distancia infranqueable entre la conciencia de Elisa y el entorno que la sostiene: "Su mente se ha transformado en una piedra opaca, compacta, de la que no salen ni entran pensamientos, y que parece no poder establecer ninguna relación con ese exterior brumoso y ardiente que llena todo el horizonte visible." 4

Florencia Abbate ${ }^{5}$ señala que las experiencias límites de los personajes en Nadie nada nunca son contadas como cuadros estáticos en los que se trata de cristalizar, mediante una descripción fenomenológica extremadamente detallada, la densidad de un instante carente de movilidad y atemporal. Volcado en lo efímero de un instante, el ejercicio de descripción de Saer explora las vivencias de lo insondable. En estos casos, las vivencias retratadas remiten a estados subjetivos en los que predomina, de un lado, un desvanecimiento de la capacidad aprehensora y significante de la conciencia como en la ensoñación, el insomnio y la pasividad extrema, y, del otro, como su correlato, la presencia de un espesor inescrutable caracterizado recurrentemente a través de adjetivos como lo "nocturno", "vacío", "anónimo", "opaco", "informe”, "inmóvill, "sombrío", "denso", "impreciso", "confuso", "silencioso", “inerte", "ardiente", "sofocante", "negruzco", "neutral", etc. Asistimos entonces al despliegue de un discurso que intenta aprehender mediante rodeos del lenguaje acontecimientos que exceden las posibilidades de la conciencia objetivante. La escritura saeriana intenta penetrar en estos pliegues diacrónicos de la existencia de los personajes y, en este sentido, su obra se torna compatible con la metodología levinasiana, es decir, con una hermenéutica abierta que no se rinde ante la imposibilidad de plasmar en un discurso claro, coherente y definitivo la totalidad de las experiencias subjetivas.

En estrecha conexión con lo anterior, el estilo abierto de la escritura se verifica también en la intertextualidad que define la obra de Saer, que -como pasa con la novela que analizamos, el secuestro y desaparición de la pareja protagonista sugerido sobre el final del relato es explicitado y esclarecido en obras posteriores como Glosa, La pesquisa o La grande-, una novela es retomada

\footnotetext{
${ }^{4}$ Saer, Juan José, Nadie nada nunca, Buenos Aires, Seix Barral, 2011, p. 135.

5 Ver: Abbate, Florencia, El espesor del presente. Tiempo e historia en las novelas de Juan José Saer, Villa María, Eduvim, 2014.
} 
y re-dicha por otra, a partir de voces, circunstancias y tramas diferentes. Sobre este aspecto, Teresa Gramuglio observa que la producción de este autor convoca a una "lectura por lo tanto abierta, aceptadora de su correspondiente dosis conjetural, seguramente modificada y aun contradicha por nuevas lecturas, por nuevos textos"; 6 y agrega, "el conjunto de las narraciones de Saer funciona a modo de una vasta obra abierta que permite nuevas incorporaciones, remisiones, ampliaciones, avances y retrocesos. Una totalidad siempre en marcha, cuyo cierre parecía postergarse indefinidamente. Sólo la muerte de Saer pudo cerrarla". 7

En suma, la escritura de Saer en Nadie nada nunca se desarrolla de acuerdo con un pensamiento diacrónico cuya singularidad consiste en intentar abarcar con el discurso el espesor de un lapso en el que los sujetos -los personajesestán atravesados por acontecimientos ajenos a la conciencia, pero, a la vez, constitutivos de su ser. Esta iniciativa avanza a través de una hermenéutica que, como lo explica Gramuglio, se exige abierta y que asume las particularidades recién mencionadas.

A continuación, se analizarán las ideas de continuum impersonal y de instante del presente como figuras de inspiración levinasiana y claves de interpretación del texto de Saer para el análisis de las nociones de tiempo en la obra escogida.

\section{El continuum cósmico}

El relato de Saer no avanza con arreglo a una cronología lineal y fluida. Su carácter fragmentario e intermitente se sostiene sobre recurrentes y prolongadas pausas de descripciones que detienen la continuidad de los sucesos para dar cuenta de un tiempo no-cronológico. El desarrollo de Nadie nada nunca procede a través de un repetido y sistemático detenimiento en la descripción de escenas que pueden visualizarse como segmentos inconexos que funcionan como suspensión de la narración. La tensión narración-descripción muestra la estructura discontinua de la obra y descubre una realidad anárquica en la que los personajes están insertos y que es inconmensurable con las representaciones

\footnotetext{
${ }^{6}$ Gramuglio, María Teresa, El lugar de Saer. Sobre una poética de la narración (1969-2014), Rosario, Espacio santafesino ediciones, 2017, p. 41.

${ }^{7}$ Ibid., p. 79.
} 
lógicas y cronológicas que puedan hacerse de ella. Esta dimensión anárquica de la existencia es la del ambiente en el que los personajes están arrojados de un modo ciego e inmemorial y cuya comprensión es cuando menos una labor embarazosa. Siguiendo algunas reflexiones del autor denominamos tiempo cósmico a este medio anterior a la conciencia tematizante y al que los personajes están adheridos a través de su existencia física. Saer señala en el marco de una entrevista que su "concepción (digamos mejor, mi sentimiento) es que espacio y tiempo forman una especie de continum en el cual estamos sumergidos, casi chapaleando. (...) La idea es que el espacio nos recibe o nos expele de una manera casi ciega."

De acuerdo con Saer, el cosmos es totalmente indiferente al hombre. Todos los hombres son iguales para el cosmos, porque el cosmos no se ordena con arreglo a las expectativas de ellos. Por su parte, para Levinas el cosmos es la sola existencia anónima sin perspectivas humanas (ni éticas, ni sociales, ni lingüísticas, ni de ningún tipo) al que el todo yo se encuentra arrojado y engarzado a través de su primordial entrada en la existencia que es siempre sensible o corporal. Para el filósofo esa existencia impersonal tiene la modalidad de un haber o hay (ily a) que se produce totalmente desafectado de la intencionalidad del hombre pero que, no obstante, como una "inhumana neutralidad", lo amenaza con absorber la subjetividad en la indiferencia del medio. Como Saer, cuando se refiere al continuum cósmico en el que están anclados los personajes desde siempre, las figuras de la noche y de la neutralidad inhumana constituyen los dos aspectos con los que el lituano caracteriza lo propio del il y a. La imagen de la noche, opuesta a la iluminación de la conciencia, representa la presencia sin luz de un trasfondo de existencia que ejerce su hegemonía sobre los entes. La noche del ily a entraña una plenitud que Levinas llama "plenitud de vacío". El sentido de esta "plenitud" enfatiza la indeterminación radical de lo nocturno. El vacío es pleno en tanto transcurre como imposibilidad absoluta de establecer una determinación óntica capaz de interrumpir el decurso impersonal de la existencia. Lo indeterminable de la noche cancela la posibilidad de que por la noche misma se produzca el acontecimiento de una interioridad capaz de poner entre paréntesis, al menos por unos instantes, la continuidad impersonal de la existencia pura:

${ }^{8}$ Saer, Juan José, Una forma más real que la del mundo, Buenos Aires, Mansalva, 2016, p. 55. 
...como una atmósfera densa, plenitud del vacío o murmullo del silencio. Tras esta destrucción de las cosas y de los seres queda el "campo de fuerzas" del existir impersonal. Algo que no es sujeto ni sustantivo. El hecho de existir que se impone cuando ya no hay nada (...) Un existir que resiste sea cual sea la negación que intente desecharlo. Irremisible existir puro. ${ }^{9}$

Los esfuerzos de la razón por ordenar ese continuum informe y sin perspectivas en una continuidad racional, que es la de la cronología, es apenas una construcción artificial entre otras y no expresa la forma o esencia de esa realidad. Por caso, “....en Nadie nada nunca la discontinuidad temporal es una manera de organizar los acontecimientos, tan convencional como podría serlo una historia lineal. Y los acontecimientos son los mismos, pero es el sistema el que da un sentido particular a esos acontecimientos". ${ }^{10}$

La forma de la sucesión y de la irreversibilidad que definen la continuidad cronológica no agotan todas las formas posibles del tiempo, pues el ordenamiento lineal de los hechos es producto de una obra de la conciencia (memoria), que consiste en introducir cohesión allí donde originariamente no existe parangón con los sistemas de mensura racionales:

La noche entera está como a la expectativa, vigilando. Durante un tiempo incalculable, segundos, minutos, horas, un tiempo cuya duración es al fin de cuentas secundaria o imposible de medir ya que los intersticios que la cortan -si la cortan intersticios- no responden a ninguna clase de escala o de medida, en el pueblo dormido y desierto no pasa nada, a no ser la interrupción imperceptible que ningún oído humano, aun concentrando al máximo su atención, hubiese podido, siquiera vagamente, escuchar. ${ }^{11}$

En este pasaje, la acción no pertenece a un personaje, sino a la noche; es la noche la que vigila y en ella nada se perfila ni como sujeto ni como objeto. La plenitud de la noche hace que por ella misma nada sea percibido, ni siquiera los fragmentos que la componen. Su duración no es la misma que la temporalidad de los objetos, se presenta como "incalculable", tal vez porque

\footnotetext{
${ }^{9}$ Levinas, Emmanuel, El tiempo y el otro, Barcelona, Ediciones Paidós Ibérica, 1993, p. 84.

${ }^{10}$ Saer, J. J., Una forma más real que la del mundo, pp. 65-66.

${ }^{11}$ Saer, J. J., Nadie nada nunca, p. 64.
} 
es inconmensurable con el tiempo objetivo e "imperceptible" a los sentidos del sujeto. La continuidad que teje el relato sobre ese trasfondo oscuro en el que chapotean los personajes es una ficción de la memoria, como se puede reparar en este fragmento:

...algo en la atmósfera inmóvil y caliente deja entrever la duda de si realmente, en puntos sucesivos del amplio espacio abierto y destellante, unos minutos antes, jinete y caballo han estado llenándolo, de un modo gradual, con sus carnaduras compactas, o bien si esos volúmenes móviles que ya se esfuman de la atención, en la que son sustituidos por las imágenes de colores, no son otra cosa que una ilusión de la memoria, y nunca ba babido nada, nadie, en el gran espacio vacio y precario que, incansable, deteriora la lu₹. ${ }^{12}$

Florencia Abbate señala que en Nadie nada nunca el mundo narrativo se desintegra y se recompone a cada instante como si fuera la primera vez. ${ }^{13} \mathrm{En}$ la voz de cada personaje aislado en su experiencia propia de ese presente eterno, atemporal e indiferente, este continuиm se re-edita conforme a vivencias diferentes que cada quien hace de él. La misma autora considera que el principio formal de la novela es el de la discontinuidad del tiempo. Es el tiempo del relato el que está discontinuado por la presencia de un espacio y un tiempo que a través de la experiencia de los personajes se manifiestan inabarcables por la lógica narrativa. En este sentido, la continuidad histórica se presenta como ficcional o artificial, pues por obra de la memoria y de la imaginación la misma escena es contada de modos diferentes según la voz de los personajes y del narrador. No hay una historia común y objetiva; hay tantas historias como voces que la cuentan e imprimen un sentido al continum a-lógico del pasarse anónimo del cosmos. En este mismo sentido -entendemos nosotros- se puede ver que la discontinuidad del tiempo saeriano no reside únicamente en el corte que supone el instante del presente material que vivencian los personajes sobre el relato, al que refiere Abbate, sino también (y a la inversa) la interrupción que los propios relatos personales -las memorias individuales y/o colectivasefectúan sobre dicho continum impersonal e inhumano. Es el relato desde una perspectiva subjetiva el que discontinúa la continuidad de un instante que,

${ }^{12}$ Saer, J. J., Nadie nada nunca, p. 97 (el subrayado es nuestro).

13 Ver: Abbate, F., El espesor del presente, p. 78. 
como veremos a continuación, tiene la forma de una eternidad despersonalizante.

En efecto, Abbate utiliza, junto a otros autores, la noción de instante para dar cuenta del modo en que sus personajes vivencian el contacto con ese continuum impersonal. Seguidamente analizamos el sentido filosófico de la categoría de instante como posible clave hermenéutica de la dimensión temporal de la novela.

\section{La figura levinasiana de instante como clave hermenéutica de Nadie nada nunca}

La discontinuidad del relato en Nadie nada nunca deja emerger, a través de imágenes poéticas, el presente o "ahora" eterno que congela la existencia de los personajes en una situación de extrañamiento del entorno y de sí mismo. En cada uno de esos paréntesis, los personajes se exhiben como entes inmersos en un tiempo estrictamente subjetivo sin conexión con el mundo exterior inaccesible e incierto. Para dar sentido a estos paréntesis, Florencia Abbate retoma el concepto de instante que Gastón Bachelard desarrolla en La intuición del instante. Siguiendo a Gastón Roupnel, Bachelard afirma que el instante es el elemento primordial del tiempo y tiene un carácter absolutamente puntiforme, es decir que carece de dimensiones internas como pueden ser los horizontes de pasado o de porvenir. ${ }^{14}$ A contracorriente del vitalismo bergsoniano que Bachelard pone en discusión con Roupnel, la duración no es el elemento fundamental que explica la constitución del tiempo, sino a la inversa; el tiempo tiene un carácter absolutamente discontinuo. La duración está hecha a partir del instante que dimensiona en pasado y porvenir a partir del hábito y de las asociaciones de la imaginación. De modo que las perspectivas temporales consideradas independientemente del instante no serían más que meros fantasmas. El recurso a la noción bachelardiana de instante es fecundo al ejercicio hermenéutico de Abbate porque, primero, propone un fundamento del carácter esencialmente discontinuo del tiempo como aparece en la novela; segundo, dicha discontinuidad se funda en el elemento primordial del tiempo que es el instante puntiforme suspendido en la nada, sin puentes de

14 Ver: Bachelard, Gastón, La intuición del instante, México, Fondo de Cultura Económica, 2002. 
comunicación con otros instantes. En este sentido, la continuidad temporal es un artificio del intelecto en Bachelard, tal como lo propone insistentemente Saer en Nadie nada nunca. Tercero, a través de esa idea de instante se puede explicar el aislamiento y encierro de los personajes en su propia subjetividad, transidos por el extrañamiento que les produce el medio que los contiene. En efecto, la soledad ontológica que hace al instante de auto-referencialidad ofrece un enfoque posible para dar cuenta del fenómeno que estaría describiendo Saer cuando interna las descripciones en intersticios de la existencia cotidiana que se vuelven cada vez más espesos y oscuros.

Por otra parte, según la lectura de Abbate que aquí compartimos, la propia conciencia del yo es pensada en complementariedad con la figura del instante. Según las palabras de la autora, "la temporalidad de Nadie nada nunca parece cercana a esta idea de que la conciencia es conciencia del instante" ${ }^{15}$ Desde nuestra perspectiva, la noción levinasiana de instante es ventajosa para interpretar la relación entre el nacimiento de la conciencia y el presente eterno y acrónico de donde emerge el yo; algo para lo que el enfoque de Bachelard no ofrezca tal vez claves de lectura filosóficas suficientes.

La idea de instante se desarrolla especialmente en las obras tempranas de Levinas publicadas en la década del '40, especialmente en De la existencia al existente. En esta obra, el instante es el lapso en el que el yo emerge de una dialéctica (lucha) entre un impulso o conatus que pugna por adueñarse de la existencia y la ejecución anónima del tiempo cósmico que amenaza con reducir su singularidad al trasfondo homogéneo, neutro e impersonal del existir puro, esto es, el existir mecánico y meramente orgánico de los cuerpos físicos. Esta concepción del instante tiene la ventaja de conservar las notas de interrupción, evanescencia, auto-referencialidad y clausura sobre sí como se advierte en Bachelard, pero aporta, además, una descripción de su estructura y dinámica interna mediante la cual se da cuenta del nacimiento mismo de la conciencia. $\mathrm{Si}$, como nosotros pensamos, Abbate tiene razón al afirmar que la conciencia es conciencia del instante; Levinas deviene un recurso fructuoso para entender cómo se lleva a cabo la conciencia a partir del instante.

No obstante, cabe subrayar un elemento no menor a los fines de nuestro objetivo de aplicación de la noción levinasianana de instante a la lectura de Nadie nada nunca, y es que la propia génesis de dicho concepto en la obra del

${ }^{15}$ Abbate, Florencia, El espesor del presente, p. 78. 
filósofo deviene una herramienta notablemente fecunda para comprender la riqueza del instante de discontinuidad en el texto de Saer. Esto se debe a que en el pensamiento del propio Levinas el concepto de instante es objeto de una reconceptualización que nos permite dar cuenta de los dos sentidos que parece recobrar la vivencia del lapso en la novela; a saber, por un lado, el de la posición del yo en la existencia como un hacerse cargo del propio existir en cuanto obligación ineluctable y por el que se interrumpe la monotonía e impersonalidad cósmica; por otro lado, el instante también significa la posibilidad de la sutura del tiempo como relación con la trascendencia. El primero de los sentidos de instante, es el que podemos reconstruir sobre todo a partir de los textos del lituano De la evasión (1935) y De la existencia al existente, el segundo de los sentidos mencionado, el instante de la producción originaria del tiempo a partir de la relación con el otro, en este caso con la otra, la amante, se configura especialmente a partir de otra publicación de fines de los '40, El tiempo y el otro (1948) y continúa desarrollándose hasta las obras de madurez, especialmente en De otro modo que ser o más allá de la esencia (1974). De manera sumaria podemos decir que en Levinas el instante es un acontecimiento de alteridad, pues el primer sentido de instante como desprendimiento del existente respecto del existir puro -nacimiento del yo- señala la posición de otro respecto del continuo cósmico; una primera diferencia. El segundo sentido del instante, en cuanto acontecimiento de la alteridad irreductible de la que pende el propio tiempo, es el evento de la alteridad del otro respecto del Mismo que mediante su existencia sensible se separó antes del trasfondo físico impersonal.

A continuación, en esta sección, analizaremos la descripción saeriana del instante de pesadez de la posición de los personajes en la existencia utilizando la figura filosófica del instante levinasiana compuesta en los primeros trabajos del autor recién citados. Y, dejaremos el análisis de la segunda noción saeriana de instante como sutura del tiempo con arreglo a la figura levinasiana del instante como acontecimiento de la trascendencia para desarrollar en el último apartado.

\subsection{El instante como posición del existente}

El progreso del relato de Nadie nada nunca se suspende en el abordaje de los puntos temporales en los que la mera existencia de los personajes -su sólo 
hecho de ser- se plantea como un esfuerzo por despegarse de un trasfondo en el que parecen estar clavados. Ser o existir como un yo y/o como un ente singular implica, de este modo, sobreponerse a un enfrentamiento con el continnum cósmico en el que el acto de existir está absorbido. El instante, es este acontecimiento agónico del que nace la singularidad del ipse como resultado de un encuentro y reyerta con el tiempo cósmico.

El trasfondo cósmico levinasiano o saeriano es el horizonte al que los hombres están pegados y del que los personajes de Nadie nada nunca pueden arrancarse a cada instante para ser ellos mismos, pero no de manera gratuita y sin esfuerzo. Así se observa en los siguientes segmentos:

Salgo, salimos del hundimiento impensable, como de un pantano. Y mis piernas, trabajosas, la izquierda, la derecha, la izquierda ahora, la derecha ahora, a través de las puertas negras me llevan, como si no hubiese ninguna razón, a la ventana de enfrente que da, ahora puedo verlo, a la playa. ${ }^{16}$ ...todo, mientras deambulo sin fin preciso por la casa, pareciera estar acabando de salir, de emerger, trabajoso de algo negro, sin forma, innominado. Por fin veo el cenicero de barro cocido, en el suelo, en la pieza principal, y me acuclillo. A su lado, sobre las baldosas coloradas, está estampada la mancha negra. También ella acaba de salir, recién venida, de lo negro, o es como un rastro que lo negro, por una de sus grietas, ha dejado pasar. No tiene historia. Es una mancha negruzca sobre una baldosa colorada, junto a un cenicero de barro cocido, en una habitación blanca, en este instante en que fluye una luz particular. ${ }^{17}$

Un grito llega, súbito, de la playa, quebrando, discontinuo, saliendo de su nada sin buscar, en apariencia, un destino preciso, emisión neutra de voz que alguien saca de lo negro no por decir algo sino por ver cómo, de a sacudones, entrecortada, la vOz nace. ${ }^{18}$

Manteniéndonos en la línea interpretativa levinasiana, la expresión de Abbate de "conciencia del instante" se puede reinterpretar como el acontecimiento de la conciencia que se posiciona como tal al asumir (a su pesar) el existir anónimo como un existir propio, transido por las afecciones que el

\footnotetext{
${ }^{16}$ Saer, J. J., Nadie nada nunca, p. 35.

${ }^{17}$ Ibid., p. 55.

${ }^{18}$ Saer, J. J., Nadie nada nunca, p. 77.
} 
medio imponga a esa subjetividad. ${ }^{19} \mathrm{El}$ instante es la faena, a la que estaríamos ligados por el solo hecho de ser, de cargar con la existencia dándole, de ese modo, una dimensión singular que denominamos interioridad. Instante de nacimiento del ipse que el lituano describe como una "conquista del ser que recomienza perpetuamente, como si ella pasase dentro del tiempo cartesiano con los instantes discretos, cada uno de los cuales viene de la nada". ${ }^{20} \mathrm{La}$ conciencia, en cuanto conciencia del instante, no tiene al instante como objeto de representación, ella nace en el acontecimiento del instante marcando un inicio, comienzo o presente que fisura la continuidad monótona de la existencia física (continum impersonal). Es en este sentido que consideramos fecundo introducir la significación levinasiana del instante para dar lectura a los ahoras atemporales de Nadie nada nunca.

En resumen, la diacronía del instante es lo que parece perseguirse en la discontinuidad del relato de Nadie nada nunca a través de una escritura que hemos dado en llamar "diacrónica". La penetración en cada uno de estos instantes discontinúa el relato para mostrar, por un lado, que su continuidad es artificial o secundaria y, por otro, que el constante y discontinuo nacimiento del yo entraña una faena intestina al hecho de ser o de estar en la existencia.

La posición de la conciencia que "salta" laboriosa del continuum impersonal es experiencia de la situación límite del aislamiento de los personajes en sí mismos -en su propia realidad y determinación física o material- bajo riesgo de quedar disueltos en un trasfondo indiferenciado donde los individuos pierden su condición de sujeto y adquieren el mismo estatuto ontológico que el resto de los entes. Esta es la amenaza de despersonalización que vivencian los personajes de la obra en diferentes situaciones y cuyo sentido tanto ontológico como político nos proponemos examinar en el siguiente apartado.

19 Toda la obra De la existencia al existente es, más que ningún otro texto del autor, un tratamiento sobre el instante concebido como ruptura de la continuidad sea de la materia, sea del relato. En ese instante, que a lo largo de la amplísima obra del autor se cargará de capas de sentido diferentes, se sitúa siempre la descripción del advenimiento del yo y el anudamiento de la subjetividad ética.

${ }^{20}$ Levinas, Emmanuel, De la existencia al existente, Madrid, Arena Libros, 2000, p. 24. 


\section{El fenómeno de la despersonalización: aspectos ontológicos y políticos}

Nadie nada nunca exhibe los instantes de confusión del yo con el entorno físico indeterminable y sin lógica ni cohesión interna. El contacto con este existir impersonal amenaza con la extinción del sujeto, porque dicho contacto no es el de la relación sujeto-objeto -vinculo privilegiado por el pensamiento moderno para determinar lo distintivo del sujeto-, sino el de una participación compelida a un ejercicio de existir del que no es fundamento, es decir, al que no ha dado inicio ni tiene la libertad de abandonar. Determinado por un exterior sobre el que no tiene dominio, el yo es, en esos instantes, una existencia material que pierde su condición subjetiva y se confunde con el resto de los entes cuyo modo de ser está físicamente determinado sin posibilidad de revocación. El instante en el que el yo se roza con la exterioridad inefable que lo contiene y absorbe pone en riesgo su unicidad personal y constituye una amenaza de despersonalización que consiste en la imposibilidad de distinguir una interioridad de una exterioridad y de recortar la identidad de las cosas y de sí mismo.

Para Saer este fenómeno de despersonalización es "lo esencial de la vida de nuestro tiempo"; y, al respecto, declara categórico: "yo quería escribir sobre eso porque lo siento así". ${ }^{21}$ En el marco de unas entrevistas realizadas en el año 2000, el escritor identifica la despersonalización con "una pérdida del sentido de lo interior y lo exterior, como si no se supiera bien quién contiene al otro", ${ }^{22}$ desdibujando la definición del yo como sujeto que, por definición -desde la modernidad a esta parte- es concebido como el soporte y fundamento de sí mismo y de todo cuanto lo rodea en tanto representaciones suyas. En ese mismo contexto, el autor asocia la despersonalización con la soledad o al aislamiento en el que el sí mismo, fragmentado de los demás y expuesto a una exterioridad del medio, vivencia la disolución de su propia sustancialidad.

La novela reconstruye situaciones límites de estar adherido a un trasfondo gomoso, pegajoso y oscuro del medio que produce extrañeza y terror:

${ }^{21}$ Saer, J. J., Una forma más real que la del mundo, p. 90.

22 Ibid., p. 142. 
Y de golpe, en ese amanecer de octubre, su universo conocido perdía cohesión, pulverizándose, transformándose en un torbellino de crepuisculos sin forma, $y$, tal vez sin fondo, donde ya no era tan fácil buscar un punto en el cual hacer pie, como uno podía hacerlo cuando estaba en el agua, sentía menos terror que extrañeza -y sobre todo repulsión, de modo que trataba de mantenerse lo más rígido posible, para evitar todo contacto con esa sustancia última y sin significado en la que el mundo se habia convertido. ${ }^{23}$

"Y de golpe" el cosmos deja de verse como un universo ordenado u ordenable y se transforma en un torbellino informe, carente de perspectivas y sentido; y los objetos dejan de tener el espesor de entes identificables para volverse apenas puntos dispersos en un vacío oscuro que suspende la posibilidad del tiempo del relato en el que transcurre y se narra la vida personal y colectiva del individuo. Las descripciones de estas situaciones límites en las que los personajes están próximos a hundirse en la "sustancia última y sin significado" de una realidad que "no tiene historia". Son instantes sin el ritmo cronológico, cuya duración no se puede medir con los esquemas que elabora la conciencia:

La noche entera está a la expectativa, vigilando. Durante un tiempo incalculable, segundos, minutos, horas, un tiempo cuya duración es al fin de cuentas secundaria o imposible de medir, ya que los intersticios que la cortan -si la cortan intersticios- no responden a ninguna escala o medida, en el pueblo dormido y desierto, no pasa nada. ${ }^{24}$

Cuando el pueblo duerme, la noche es la que vela -vigila-; y el ejercicio anónimo de la vela no transcurre en el tiempo, no se mide con las escalas cronológicas humanas. Ese tiempo no-humano es el que Levinas denomina eternidad. Este filósofo utiliza la idea de insomnio para describir el estado de una conciencia que está pegada a la noche del ily a sin poder separarse de ella bajo riesgo de perder su condición de sujeto. Pues en el insomnio no es la atención del sujeto la que dirige la vigilia, es la noche la que vela y obliga al yo a no separarse de ella.

\footnotetext{
${ }^{23}$ Saer, J. J., Nadie nada nunca, p. 123.

${ }^{24}$ Ibid., p. 64.
} 
Observamos en el sueño y en la ensoñación aludidos en Nadie nada nunca figuras paralelas a la del insomnio levinasiano; ellas grafican, a veces, el carácter inescrutable de la exterioridad, pero, sobre todo, la labilidad de la interioridad o del sí mismo:

A veces formaban una línea, vacilante, a la que sacudía una ondulación imperceptible, pero casi de inmediato la línea se cortaba, convirtiéndose en ese número impreciso de puntos bailoteantes. El bañero tenía los ojos fijos en ellos. Los veía como desde un punto más acá de la retina, o de la atención, o de la conciencia, en un estado que no era del todo el de la vigilia ni tenía que ver con el sueño, pero incluso si hubiese tenido la idea de desviar la mirada y ponerse a pensar en otra cosa, lo que no ocurrió, le hubiese sido sin duda necesario un esfuerzo mucho más grande que el requerido para una decisión semejante en una situación corriente. ${ }^{25}$

La amenaza de despersonalización que se cierne sobre los personajes incluye, por un lado, la imposibilidad de la representación y del relato; y, por otro, el aislamiento de los individuos en su interioridad material sin puentes de comunicación con los otros.

El horizonte de indeterminación, en el que se disuelven los personajes, parece no limitarse únicamente al carácter ontológico del tiempo y del cosmos en el que están engarzados los personajes; las vivencias de incertidumbre se registran también en el plano social y político atravesado por el asesinato sistemático de caballos en el pueblo y la represión desatada durante la última dictadura militar argentina; contexto que Glosa descubre como aquel en el que tuvo lugar el secuestro y la desaparición de los protagonistas de la obra, el Gato y Elisa. ${ }^{26}$ El presente en el que se ahogan las subjetividades, es el presente de la represión y de la vigilancia o el insomnio político que excluye -so pena de exterminio- cualquier singularidad que se plantee heterogénea y desafiante al orden establecido.

25 Ibid., p. 122.

26 “...en junio, el Gato y Elisa, que estaban viviendo juntos en la casa de Rincón desde que Elisa y Héctor se separaron, han sido secuestrados por el ejército y desde entonces no se tuvo más noticias de ellos" (Saer, Juan José, Glosa, Buenos Aires, Seix Barral, Buenos Aires, 2017, p. 130). 
La trama enlaza la historia de los caballos con la coyuntura política evocada a través de comentarios del narrador o de personajes secundarios sobre los excesivos "desplazamientos misteriosos del ejército y de la policía" 27 y una semblanza del comisario del pueblo, el Caballo Leyva, que encarna el horror de la represión ilegal: "Y se decía también que de vez en cuando, de noche, llegaba algún coche particular a la comisaría del que sacaban a empujones a algún hombre esposado para que el Caballo, con sus métodos especiales, lo hiciera hablar". ${ }^{28}$

Tras el asesinato de los caballos y, especialmente, del zaino del Caballo Leyva, "flotaba un ambiente de desconfianza general"29 que se agravó con la muerte del propio comisario y a raíz de lo cual "el ejército había tomado la cosa en mano; operación de rastrillo en toda la provincia; el pueblo, aislado del universo." 30

El aislamiento general del pueblo, sometido a una brutal requisa y régimen de observación excluyente de cualquier pliegue de intimidad y secreto, sugiere la reducción política y militar del pueblo a un orden de vigilancia plena supresora de cualquier expresión que no se adecue al sistema. Esta vela remite una vez más al concepto de il y a que Levinas define como una exigencia de "presencia plena" que "oprime", al extremo de no permitir que nada emerja como una excepción al monótono transcurrir del existir impersonal. Esta opresión garantiza la ausencia de cualquier acontecimiento -un discurso o palabra - que interrumpa la gesta anónima del ser y destaque una perspectiva nueva. En estas condiciones, el cosmos político se presenta para los personajes semejante al cosmos material, es decir, como una continuidad desprovista de diferencias internas y al que se encuentran adheridos cual puntos del espacio nocturno que no se refieren unos a otros. Así como la realidad material se descomponía para el bañero en un "torbellino de crepúsculos sin forma" y "sin fondo", los personajes, sumergidos en el instante de su experiencia subjetiva, permanecen insertos en un cosmos donde "no hay perspectiva" $y$ [donde] "esos puntos no están situados. Es un hormigueo de puntos". ${ }^{31}$ Cada quien, encerrado en la

\footnotetext{
${ }^{27}$ Saer, J. J., Nadie nada nunca, p. 148.

${ }^{28}$ Ibid., pp. 107-108.

${ }^{29}$ Ibid., p. 110.

30 Ibid., p. 193.

${ }^{31}$ Levinas, E., De la existencia al existente, p. 96.
} 
soledad ontológica del instante por el que y en el que quedan emplazados en la existencia como existentes singulares, padecen el malestar de estar pegados a sí mismos, sin puertas ni ventanas de salida hacia ningún lado ni hacia nadie. Esta situación representa para Levinas lo propio de la existencia finita del hombre, que solo alcanza superación a través de la socialidad con los otros totalmente ajenos a su interioridad. El otro, para el lituano, libera del aprisionamiento del instante y la relación con él es vínculo con un instante nuevo, un futuro puro o, sencillamente, tiempo. Carente de experiencia interpersonal, el yo aislado es una existencia enclavada en un instante sin tiempo y, por ende, sin historia. Dicho en otras palabras, la hegemonía del instante conlleva un repliegue del discurso, de la memoria y del relato.

Este cuadro reedita también la noción levinasiana de insomnio, cargándola ahora de un sentido político. La presencia plena de la vigilancia continua aísla tanto al pueblo del resto del universo, como a los individuos del resto de la comunidad. El orden externo impregna de ese modo la vida subjetiva colectiva y singular sin que aquellos que la sufren puedan asumirlo y hacerse cargo de él; pues dicho orden continúa siéndoles extraño. Siguiendo a Levinas, esta intimidad con el ser puro - que en el contexto de la novela vemos representado en la exposición de los personajes a la vigilancia continua-inviste al sujeto y le impide toda intimidad consigo mismo. El estado de vigilancia, que no viene de una decisión del sujeto sino de una imposición del afuera, es una intimidad alienante que quita al yo toda posibilidad de obrar en su nombre y manifiesta una "extinción del sujeto." 32

De acuerdo con nuestra lectura, la pesadez del ambiente que absorbe a los personajes dejándolos en un estado de incomprensión general, como la conciencia de Elisa que es dura e impenetrable como una piedra, es explícitamente material. Es el aire, el calor, la oscuridad de la noche, la pesadez de los cuerpos, etc., los que sofocan y aturden la conciencia. Pero la insistencia de esas imágenes y del riesgo siempre presente de la extinción del sujeto -vuelto piedra, ambiente o cosa- puede interpretarse como una estrategia estética para aludir, a través del género de la ficción y de un discurso no realista, al peligro cercano, inminente pero imprevisible de la muerte y la desaparición en el presente de la dictadura. Una reflexión sobre el presente refractario a la razón y la exploración tan literaria como fenomenológica de los instantes en los que

${ }^{32}$ Ibid., p. 111. 
se decide la realidad subjetiva de los entes en pugna con el cosmos, son, conjeturamos, recursos posibles para pensar, sin aspiración a decirlo todo o de agotar los sentidos, el presente político de la dictadura.

Si bien son varias las referencias al contexto de represión, aparecen sin embargo de manera fragmentaria sin una mención clara y coherente acerca del accionar de los militares, de la policía, del destino de los detenidos, de la sugerida articulación entre las fuerzas de seguridad y los políticos, de los grupos llamados guerrilleros e, incluso, del futuro inminente del Gato y Elisa sobre el final de la novela cuando el Ejército se acerca a la casa. Este conjunto de interrogantes que quedan en el margen de lo no-dicho queda a veces sugerido y otras como una deuda que se salda en futuras obras; como el relato de la desaparición de la pareja.

En la economía del texto esas elipsis pueden asumir, desde nuestra perspectiva, la función de señalar lo que Levinas nombraba con la expresión "mundo roto"; 33 una ruptura entre la experiencia subjetiva y la realidad sociopolítica tan extraña e impenetrable para el lenguaje como la naturaleza informe e indeterminable del continum cósmico. ${ }^{34} \mathrm{La}$ incertidumbre que rodea el presente de la obra es relativa a dos cosmos u órdenes, uno, el ontológico vinculado a la realidad material de los seres humanos y del tiempo y el espacio en sí mismos, y otro, el orden político que se cierne opresivamente sobre los individuos que carecen de la posibilidad de anticipar los modos y tiempos de su despliegue.

En el presente de la novela el horizonte de sentidos compartido que garantiza la comunicación entre los interlocutores -el mundo- está roto. Los significantes se vacían de significados o sentidos capaces de reunir a las cosas y a los hombres entre sí. Esta cancelación del discurso, o de su eficacia, es uno de los rasgos que Levinas confiere al existir monótono e impersonal que reduce

\footnotetext{
${ }^{33}$ Ibid., p. 23.

${ }^{34}$ La noción de "mundo roto" o "mundo trastornado" remite a un estado de cosas en el que predomina "la impenetrabilidad recíproca de los espíritus opacos como la materia, la multiplicación de lógicas, absurdas unas para otras, la imposibilidad de un yo de juntarse con el tú, y, por consiguiente, la incapacidad de la inteligencia para aquello que tendría que ser su función esencial..." (Ibid., p. 23). Circunstancia que sin duda admite una connotación histórico-política en el autor que algunos párrafos antes, en el prólogo, advierte que estas investigaciones fueron redactadas en su mayor parte durante su cautividad (Stalag) como prisionero de guerra francés (Cfr.: Ibid.).
} 
a su lógica de ejecución a todo ente, previo a cualquier concurso de la voluntad o de la razón. El espacio intersubjetivo en el que se urde -no sin conflicto- el plexo de sentidos en el que se desarrolla la vida colectiva está bajo vigilancia.

El tiempo se abisma en los instantes y pierde su virtud narrativa. Fuera del campo intersubjetivo, en la dimensión personal de la relación erótica, el personaje central de la novela, el Gato, parece recuperar la continuación de un tiempo ya íntimo y privado a una comunidad de dos.

\section{Del instante al tiempo o la diacronización ética del instante}

Los sucesos centrales que tejen la intriga de la novela no se inscriben en una temporalidad precisa. El asesinato de los caballos, del zaino de Leyva y del propio Leyva se suceden en una relación de antes y después que el texto no hace corresponder con días ni fechas específicas. El tiempo de los acontecimientos que bien podrían entrar en una cronología concreta y puntualizada conserva, no obstante, cierto grado de indeterminación. Los episodios sobre los que se habla en el pueblo y refieren versiones diferentes no datan el tiempo. En este sentido, es factible apuntar que ellos pertenecen, de alguna manera, a una duración continua y homogénea análoga a la del tiempo cósmico que analizamos en la segunda sección de este trabajo.

La eternidad del continuum cósmico parece interrumpirse con la llegada de la alteridad de la amante, Elisa. El continum se corta con la aparición intermitente de Elisa que da sentido al tiempo y que hace pensar que en esta obra el tiempo no precede a los hombres y a la relación entre ellos; al contrario, que son los acontecimientos humanos o inter-humanos los que significan al tiempo mismo.

Las páginas que anteceden al encuentro del Gato con Elisa están cargadas de imágenes de "inmovilidad", "suspensión" y de un "silencio hirviente" 35 en el que está inmersa toda la región. Todos estos aspectos de fijeza, monotonía y silencio se revierten con el arribo de Elisa y marcan una diferencia con el resto del texto, pues es el punto en el que se interrumpe toda la inmovilidad y se produce una datación temporal.

Veamos: Antes de dicho arribo, el Gato permanece en un estado de somnolencia continuo y el solo hecho de ser o de estar acostado en una

${ }^{35}$ Saer, J. J., Nadie nada nunca, pp. 36-37. 
reposera, con los brazos y la cabeza colgando, es representado como una faena. Aunque permanece quieto, tendido bajo el sol, "por la posición de su cuerpo parece como sometido o como desafiante a esa luz ardua que lo trabaja". ${ }^{36}$ Inmóvil, expuesto al ambiente sofocante que lo envuelve, hay, sin embargo, cierto esfuerzo y un trabajo que no proviene de una acción concreta del personaje, sino del simple hecho de ser del sujeto que soporta la afección que la luz y la temperatura producen sobre su cuerpo absolutamente pasivo. La descripción pasa sin solución de continuidad del estado corporal del Gato al detalle de la pasividad de una rueda en desuso que está simplemente ahí, ni siquiera a la espera de nada, inerte y expuesta también a la corrosión que el medio producirá sobre ella. Según Levinas, la exposición sin reservas y totalmente pasiva a estas afecciones son las notas con que los hombres se encarnan en la existencia; como arrojados y adheridos a ella, soportándola. Esta faena del forzoso hacerse cargo de la existencia material fue interpretada filosóficamente a partir de la figura de instante de Levinas como posición del ipse. Pero en este apartado intentaremos aplicar el segundo sentido del instante como acontecimiento de la trascendencia a partir de la cual recobra sentido el tiempo del relato. Como intentaremos mostrar, sólo la relación con la alteridad permite al yo ir más allá del instante agónico en el que el yo se debate con el existir puro y se reconfirma a sí mismo ininterrumpidamente.

En El tiempo y el Otro, Levinas lleva adelante una diacroniazación ética del instante definiéndolo como el acontecimiento de alteridad que afecta al Mismo bajo la forma de una diferencia irreductible y que, con el progreso de la obra del autor, se le añadirá también el sentido de un concernir ético del Mismo por el otro. ${ }^{37} \mathrm{La}$ alteridad del otro es un futuro absoluto respecto de la existencia del sí mismo que Levinas y Saer describen como una iteración hastiosa, solitaria y sofocante. Sobre este punto, el lituano escribe que "la relación con el porvenir, la presencia del porvenir en el presente también parece cumplirse en el cara a cara con el otro. La situación del cara a cara representaría la realización misma del tiempo; la invasión del porvenir por parte del presente no acontece al sujeto solitario; sino que es la relación intersubjetiva". 38

\footnotetext{
36 Ibid., p. 37.

37 Ver especialmente De otro modo que ser o más allá de la esencia.

${ }^{38}$ Levinas, Emmanuel, El tiempo y el otro, p. 121.
} 
$\mathrm{Y}$, en efecto, el despabilamiento del Gato se realiza conforme a la aproximación de Elisa al pueblo:

y ahora, aproximándose, desembarazándose de a poco de los estratos de distancia que lo acolchan cada vez menos, que van dejándolo libre a medida que avanza, ensanchándose, y volviéndose más complejo y más fuerte, el ruido de un motor de automóvil que saca al Gato, de un modo gradual, de su especie de sueño.

$(\ldots)$

- ¿Así que ya es sábado? - Dice el Gato

- Sábado, sí. Efectivamente. ${ }^{39}$

El otro -la amante- es el factor que parece introducir el tiempo cronológico y la posibilidad de narrar una historia. Es importante notar que el "silencio hirviente" se suspende tras el encuentro de los amantes y se hace lugar a la palabra que ocupa algunos de los escasos y breves diálogos que se presentan en el libro. El discurso se agrega entonces como una interrupción de la densidad anónima y continua del existir puro (vacío de objetos y de sujetos), y dinamiza el relato. Así como la linealidad del relato está interrumpida por las descripciones que se detienen en la singularidad del presente atemporal -al que refiere Abbate como un "ahora eterno"- fragmentando el discurso, la aparición del otro comporta también un instante en el que se detiene (se discontinúa) la adhesión compelida del sujeto a ese "ahora eterno" y recibe tiempo y posibilidad de relato.

Saer ilustra el concepto levinasiano de instante diacrónico y, a su vez, los desarrollos levinasianos sobre dicho instante son un recurso filosófico potente para pensar en la densidad de estos instantes de discontinuidad y continuación en la novela.

El reiterado inicio de los capítulos con la leyenda "No hay, al principio, nada. Nada. El río liso, dorado, sin una sola arruga...", nos envía a la imagen de esa densidad primordial oscura y vacía en la que por sí misma no ocurre ni emergen ni sujetos ni objetos. Los personajes se separan de esa densidad con esfuerzo, como los gritos, y las cosas que llegan a la superficie manchadas de oscuridad. Pero es Elisa, la alteridad -en este caso, erótica- la que fija en el

${ }^{39}$ Saer, J. J., Nadie nada nunca, p. 38. 
relato la marca temporal concreta. ${ }^{40}$ Con su llegada, el Gato significa el presente cronológicamente como sábado y se resitúa en el tiempo del relato.

En Nadie nada nunca la alteridad erótica tiene una significación temporal de hiato o lapso que corta la continuidad impersonal y anónima introduciendo sentido a la cronología que narra la vida del personaje central. La presencia de Elisa extrae al Gato de la existencia de la que no logran sacarlo los otros, a quienes alude a menudo como a cuerpos que se mueven en diferentes sentidos y que, si bien atestiguan una existencia personal, no establecen en sentido estricto una relación inter-personal con él. La sensibilidad erótica de lo femenino encarnada en el personaje de Elisa, comporta una trascendencia respecto del continuo en el que la subjetividad del Gato está sumida. Esa trascendencia tiene, por un lado, el carácter de resistencia a la absorción en el trasfondo neutral e informe del cosmos y, por otro, el sentido de redención del amante de su encierro en el instante de soledad y aislamiento en una inmanencia que es lucha por tomar distancia de la exterioridad anodina. De este modo, la trascendencia de lo femenino es la única alteridad real o genuina que interpela al protagonista de la novela de un modo diferente al que lo hacen el resto de los objetos y sujetos en el relato, pues ella es el acontecimiento a partir del cual tiene sentido (datar) el tiempo. En otros términos, el lector no sabe que Elisa llega a Rincón porque es sábado; a la inversa, sabe que es sábado porque llegó Elisa. Ella -la amada en cuanto tal- es el acontecimiento de trascendencia clandestino y diacrónico- cuya manifestación trasciende la impersonalidad del cosmos, fisura el orden de la "inhumana neutralidad" y despierta al amante del presente eterno del insomnio privado de palabra y de tiempo.

40 A propósito de la función de la sensibilidad erótica en la constitución del tiempo, pueden consultarse los siguientes artículos: Garrido Maturano, Ángel, "El eros como trascendencia no ética y tránsito fecundo. Lectura de la fenomenología del eros de E. Levinas", Thémata. Revista de Filosofía, No 18 (1997), pp. 75-90; Palacio, Marta, "Una lectura feminista de la 'fenomenología del Eros' levinasiana", Anatellei, № 18 (2007), pp. 105-123; y Suazo, Gisela, "El desnucleamiento erótico del ipse y el futuro puro de lo femenino", Stromata. Revista de Filosofia, 1 (2017), pp. 135-151. 


\section{Reflexiones finales}

Llegados a este punto de la lectura que acabamos de proponer, quedan expuestos tres sentidos del tiempo que parecen esbozarse en Nadie nada nunca. El fluir de la realidad material a la que está adherida la existencia física del hombre es ciego e indiferente a éste. Como un vacío indeterminable de puntos inconexos que hormiguean desprovistos de coherencia, el fluir anónimo concierne a los personajes en los instantes acrónicos que detienen la trama episódica para exhibirlos pasivos e inmovilizados en un cuadro de vivencias de pesadez, sofocamiento y extrañamiento, sin nada por hacer ni comprender y donde no queda otra cosa más que salir o despegarse. El esfuerzo de los personajes por des-adherirse para reponer su condición de identidad personal constituye toda la gravedad del instante. La existencia sensible y radicalmente pasiva de los personajes se erige en una dimensión de resistencia a la monotonía y neutralidad impersonal del ser o del existir puro que arrastra al yo a una dimensión de absoluta exposición sin reservas o presencia plena, revocadora de cualquier pliegue secreto de intimidad o interioridad refractario al régimen de la exterioridad.

Adoptamos una perspectiva levinasiana para interpretar la dinámica interna del instante en la novela y su significación ontológica, política y temporal. El carácter despersonalizador que ejerce el continuum impersonal o tiempo cósmico sobre los personajes remite al efecto alienante del régimen de vigilancia continua, violenta y represiva sobre las subjetividades políticas en el presente de la dictadura. Ese presente, cual tiempo sin acontecimientos eternidad-, excluye la multiplicidad de perspectivas del discurso interpersonal y resquebraja la posibilidad de reanudar una lectura coherente y clara de las experiencias subjetivas y colectivas. La discontinuidad del texto y la fragmentación de la información relativa al contexto político indican -a nuestro parecer- esta cancelación del tiempo del relato y del lenguaje. Destituidos del nivel de lo público, la palabra y la recomposición del tiempo cronológico se refugiarán en el espacio de lo íntimo y clandestino de la vida erótica y afectiva como hemos intentado exponerlo en el último punto. 


\section{Referencias bibliográficas}

- Abbate, F., El espesor del presente. Tiempo e historia en las novelas de Juan José Saer, Villa María, Eduvim, 2014.

- Bachelard, G., La intuición del instante, México, Fondo de Cultura Económica, 2002.

- Garrido-Maturano, A., "El eros como trascendencia no ética y tránsito fecundo. Lectura de la fenomenología del eros en E. Levinas", en Thémata. Revista de Filosofía. No 18, 1997, pp. 75-90.

- Gramuglio, M. T., El lugar de Saer. Sobre una poética de la narración (1969-2014), Rosario, Espacio santafesino ediciones, 2017.

- Husserl, E., Ideas relativas a una fenomenología pura y una filosofía fenomenológica, México, Fondo de Cultura Económica, 1992.

- Levinas, E., De la evasión, Madrid, Arena Libros, 2011.

- Levinas, E., De la existencia al existente, Madrid, Arena Libros, 2000.

- Levinas, E., El tiempo y el otro, Barcelona, Ediciones Paidós Ibérica, 1993.

- Levinas, E., Entre nosotros. Ensayos para pensar en otro, Valencia, Pre-textos, 2001.

- Levinas, E., De otro modo que ser o más allá de la esencia, Salamanca, Ediciones Sígueme, 2003.

- Palacio, M., “Una lectura feminista de la 'fenomenología del Eros' levinasiana", en Anatellei. No 18, 2007, pp. 105-123.

- Saer, J. J., Nadie nada nunca, Buenos Aires, Seix Barral, 2011.

- Saer, J. J., Una forma más real que la del mundo, Buenos Aires, Mansalva, 2016.

- Saer, J. J., Glosa, Buenos Aires, Seix Barral, 2017.

- Suazo, G. (2017). "El desnucleamiento erótico del ipse y el futuro puro de lo femenino”, en Stromata, Vol. 73. No 1, 2017, pp. 135-151.

Recibido: 03/2020. Aceptado: 12/2020. 